\title{
Los entresijos dramáticos en las comedias hagiográficas de Pérez de Montalbán. El caso de El divino portugués, san Antonio de Padua'
}

\section{The Dramatic Hidden Details in the Hagiographical Comedies by Pérez de Montalbán. The Case of El divino portugués, san Antonio de Padua}

\author{
Juan Manuel Escudero Baztán \\ GRISO-Universidad de Navarra \\ ESPAÑA \\ jescudero@unav.es
}

[Hipogrifo, (issn: 2328-1308), 3.2, 2015, pp. 135-147]

Recibido: 02-02-2015 / Aceptado: 16-02-2015

DOI: http://dx.doi.org/10.13035/H.2015.03.02.09

Resumen. Este artículo se centra en los mecanismos dramáticos y rasgos genéricos de las comedias hagiográficas de Juan Pérez de Montalbán, a partir del análisis de una obra poco estudiada como es El divino portugués, San Antonio de Padua, ejemplo de excelente comedia dentro de las coordenadas del género y de las habilidades dramáticas del dramaturgo madrileño.

Palabras clave. Comedias hagiográficas, Pérez de Montalbán, género, estructura, análisis.

Abstract. This article focuses on the mechanisms and the dramatic features of the hagiographic comedies of Juan Pérez de Montalbán, from the analysis of a little-studied drama, El divino portugués, San Antonio de Padua, an excellent example

1. Este trabajo cuenta con el patrocinio de TC-12, en el marco del programa Consolider-Ingenio 2010, CSD2009-00033, del Plan Nacional de Investigación Científica, Desarrollo e Innovación Tecnológica del Gobierno de España. 
of comedia de santos gender and a good example of the dramatic art of Pérez de Montalbán.

Keywords. Hagiographic Comedies, Pérez de Montalbán, Genre, Structure, Analysis.

Juan Pérez de Montalbán² pudo escribir esta comedia entre 1621 y $1623^{3}$. Fue publicada en el Segundo tomo de sus obras de $1638^{4}$. No hay unanimidad sobre la autoría de la obra. La crítica ha venido considerando incuestionable la paternidad de Montalbán, apoyándose en la revisión que parece hizo el propio dramaturgo del tomo antes de su impresión ${ }^{5}$. Sin embargo, estudios posteriores han puesto en duda esta afirmación, en parte por la existencia de una copia manuscrita con fecha de 1623 que atribuye la obra a un tal Bernardo de Obregón ${ }^{6}$. A partir de este dato, tanto Dixon ${ }^{7}$ como Profeti ${ }^{8}$ manifiestan dudas razonables sobre la atribución a Montalbán del texto. Fuera de estas consideraciones, el objeto de las siguientes páginas se centra en otras cuestiones que atienden más a la concepción dramática de Montalbán, que a los aspectos externos de la comedia. Montalbán fue en general bastante afecto al género hagiográfico -y al género sacramental- en parte porque son géneros serios muy del gusto del público de la época, y porque resultaba en ellos muy llamativa la proliferación de una escenografía espectacular en términos materiales. De hecho, una de las características esenciales del género es la tramoya sorprendente e inverosímil en apariencia. Su empleo, contraviniendo su uso estandarizado, se comprende mejor desde la perspectiva del principio de lo verosímil cristiano, que en Montalbán como en otros autores funciona sin complejos. Dado el poco espacio que tengo aquí para mayores precisiones sobre el esqueleto dramático que sustenta la obra, señalo unas breves pinceladas a partir de cinco puntos que considero esenciales en su análisis: el papel preponderante de la teología junto a presencia de la figura del demonio; el desarrollo peculiar de las líneas secundarias de la acción; una estructuración gradual basada en la escenografía, con la inserción de lo maravilloso; la secuencia cronológica concentrada por el carácter selectivo de la materia tratada; y por último, el tratamiento particular de la figura del donaire.

2. Nació Montalbán seguramente en julio o agosto de 1601. Muere el 25 de junio de 1638, al parecer, después de haber recibido los sacramentos, según cuanto se recoge en la hagiografía inédita de su hermana Petronila, venerable madre del convento salmantino de las Franciscas descalzas (ver Zugasti, 2008, p. 188). Para más datos sobre la vida del dramaturgo, ver Dixon, 2013.

3. Ver Parker, 1952, p. 189.

4. Madrid, Imprenta del Reino, a costa de Alonso Pérez de Montalbán.

5. Ver Bacon, 1912, p. 414

6. Señalado por Paz y Mélia, 1934, p. 160, art. 1073. Dado que hay bastantes obras que refieren el mismo tema, las noticias bibliográficas al respecto son muy confusas, mezclándose en ellas referencias perdidas, atribuciones erróneas, y textos no localizados. Ver por ejemplo las trece entradas que registra Menéndez Peláez en su catálogo hagiográfico sobre el teatro español del Siglo de Oro, 2004, s. v.

7. Ver su edición de la comedia lopiana El sufrimiento premiado de 1967.

8. Ver Profeti, 1976. 
El soporte teológico de la comedia repasa temas capitales de la doctrina católica, pero mantiene, a su vez, una serie de rasgos novedosos que guardan relación con la idiosincrasia del personaje principal, definido por la tradición a través de sus continuos enfrentamientos con el demonio, así como de su brillante elocuencia como predicador. Lo primero obliga a reparar en la aparición del demonio, contrapunto del protagonista, cuyas tentaciones son siempre desenmascaradas por su santidad y vida ejemplar. Pero a su vez, esta perspectiva santificadora matiza la presentación del personaje y su relación con el mal. De entrada, se observan ciertas afinidades con el arranque de una comedia como El mágico prodigioso de Calderón, en que Cipriano y el demonio desarrollan una escena introductoria bastante parecida a la comedia de Montalbán. Pero enseguida se atisban notables diferencias. La más palpable tiene que ver con el alcance del conocimiento teológico del estudiante Fernando (trasunto juvenil del san Antonio posterior), que se manifiesta no solo no dudoso del misterio teológico que está leyendo, sino comentarista extasiado ante el enigma de la doble naturaleza de Cristo y la expiación de los pecados del hombre a través de su pasión en la cruz. Es la reflexión encomiástica de quien conoce bien los principios teológicos, no de alguien inmerso en el aprendizaje de los misterios de la revelación. En este contexto aparece el demonio sin disfraz pues aparece como «figura espantosa con cadenas» ${ }^{9}$ (fol. 155r)-, manifestando sus cualidades de ángel caído como padre de la mentira ${ }^{10}$, y como ser de inteligencia superior, poseedor de altas ciencias, capaz de antever por conjeturas lo que va a ocurrir ${ }^{11}$ (fol. 156r):

\author{
Temiendo estoy, y que tema \\ es razón, que este varón \\ me ha de hacer terrible guerra \\ si está en aquesta ciudad \\ y porque se ausente della \\ he de ponerle delante \\ mil asombros y quimeras.
}

9. Cito siempre por la edición príncipe (Segundo tomo de comedias de 1638). Manejo el ejemplar de la Biblioteca Nacional de España, signatura T/3152, que tiene mal la foliación en las primeras hojas: 155r-v, 156r-v, 159r-v, 158r-v, 161r-v..., 176r. Para evitar confusiones cito respetando la foliación original 10. «Darte respuesta / es imposible, Fernando, / porque cuando darla quiera; será mentirosa y falsa / porque aun yo no sé quien sea» (fol. $156 r$ ). Como dice Juan $(8,44)$ al respecto: «in veritate non stetit, quia non est veritas in eo, cum loquitur mendatium ex propriis loquitur, quia mendax est et pater eius»; el P. Ciruelo, en su Reprobación, ed. Ebersole, 1978, p. 36: «Cristo del diablo dice que es mentiroso y padre de mentiras»; Suárez de Figueroa, Pasajero, ed. López Bascuñana, 1988, p. 570: «me resuelvo en avisaros huyáis de la mentira como del demonio, padre suyo»; Quevedo, Sueños, ed. Arellano, 1991, p. 168: «Cuando el diablo predica el mundo se acaba. ¿Pues cómo siendo tú padre de la mentira - dijo Calabrés - dices cosas que bastan a convertir una piedra?».

11. Ver Cilveti, 1977, pp. 54 y ss. Ver, por ejemplo, Calderón, La redención de cautivos, Obras completas, p. 1330: «Y pues en la fantasía / de mística alegoría / quisiste ciego antever / siglos de futura edad»; El pastor Fido, Obras completas, p. 1586: «Luzbel: podría antever el daño / para salirle al encuentro, / ya que no a impedir la causa / a perturbar el efecto». Para todos estos tipos de demonio, ver Duarte, 2014. 
El discurso persuasivo del demonio se adorna de otros posibles subtemas como la loa a la ciudad de Lisboa'2 ${ }^{12}$. En este contexto de confrontación, el demonio se ve obligado a articular tres tentaciones sucesivas en las que amenaza a san Antonio con la persecución, la miseria, pobreza y la comisión del pecado de soberbia. Pero el demonio vacila de nuevo al señalar con reservas que conoce la guerra cruel que le espera con el santo. La posición de este último es firme desde su perspectiva espiritual, de manera que no duda en ningún momento de la visión maléfica del demonio. Su interpretación recta y cabal apareja la destrucción de cualquier atisbo de éxito en las tentativas demoníacas. Y para su refuerzo el final de la escena termina con un canto angélico, que adquiere un carácter enigmático y premonitorio (fol. 156v):

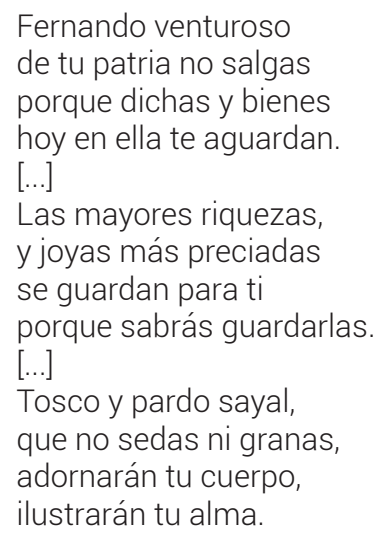

La salida al tablado de su amigo Anselmo, también estudiante, arroja luz para la comprensión completa del enigma. El cambio en la naturaleza mística del protagonista queda claramente reflejada a partir de la apariencia de ese tosco sayal que lo convierte en franciscano, preparado para el martirio y que realiza una transfiguración en San Antonio a partir de las propiedades alegóricas y salvíficas con las que se reviste (fols. 159r-v):

Pero vieras

que de sayal humilde como aroma sabea como el ámbar y almizcle salía una fragancia, [...] que eran dos disfrazados célicos serafines.

La tierra que pisaban, parecía cubrirse,

12. Recurso típico de captatio benevolentiae, dentro del género encomiástico de la loa de las ciudades «Y aun en todo el mundo / tiene fama siempre eterna / de la más bella ciudad / que el sol con las rubias trenzas / rayos de oro, si de fuego / volcanes vivos calienta: / es en efeto Lisboa» (fol. 156r). 


$$
\begin{aligned}
& \text { al levantar la planta } \\
& \text { de rosas y jazmines. }
\end{aligned}
$$

Los movimientos posteriores de las apariciones diabólicas y de la amplificación del discurso teológico tienen una estructura circular, pues vuelven a repetirse, aunque en circunstancias diferentes. El demonio se disfrazará de galán como parte del engaño que va a urdir para mantener y fomentar su control sobre el comportamiento pecaminoso y adúltero de Rosamira. Esta, embelesada por el elocuente sermón de san Antonio, abandonará el pecado, y sumirá en la frustración al demonio cuyo poder quedará estéril, a pesar de su afán por alborotar las fuerzas de la naturaleza (y abortar así el sermón del santo) y mediante la entrega de una carta con la falsa muerte del marido de Rosamira. El demonio queda entonces desenmascarado y convertido de nuevo en una figura espantosa. Claro que el motivo capital de estas escenas es el sermón divino de san Antonio, no sólo capaz de anular el poder maléfico del demonio, sino sobresaliente por su carácter excepcional ${ }^{33}$ (fol. 166v):

$$
\begin{aligned}
& \text { una lengua soberana, } \\
& \text { apacible y amorosa. } \\
& \text { Un serafín que ha bajado } \\
& \text { de los tronos celestiales, } \\
& \text { para dar a los mortales } \\
& \text { remedio contra el pecado. } \\
& \text { Una boca que parece } \\
& \text { rubio panal, que distila } \\
& \text { cándida miel, que aniquila } \\
& \text { al que en vicios se entorpece. } \\
& \text { Una trompeta sonora, } \\
& \text { que al mundo va recordando } \\
& \text { varias penas anunciando } \\
& \text { al hombre que a Dios no adora. }
\end{aligned}
$$

A la par que retoma la circularidad del discurso al asumir punto por punto aquello que leía en la intimidad el protagonista. Y cuyos motivos se centran en la salvación del hombre a partir de la historia del pecado contenida en el Génesis, la astuta serpiente que tienta a la mujer y la necesidad de la salvación a través de la doble naturaleza de Cristo, hecho carne a través de María Inmaculada, convertido en cordero de pasión que redime los pecados del hombre (fols. 172r-173r).

Bajo otro aspecto, participa de lleno Montalbán en la mecánica precisa de la unidad de acción que preconiza Lope, en tanto que varias acciones secundarias acompañan siempre a la acción principal en un punto final de convergencia. En general, se trata de una segunda acción subsidiaria que suele en algunos casos sostener una acción histórica o particular entre los protagonistas que entra de lleno en conflicto con la principal. Existen, por supuesto, multitud de variantes que permiten hablar de una aplicación bastante laxa de la concurrencia de estas acciones añejas a la principal. En Montalbán, sin embargo, esta acción secundaria adquiere

13. Hito también sobresaliente en la propia biografía del santo lisboeta. 
varias tonalidades especiales que se repiten en otras comedias suyas. En el caso de El divino portugués, san Antonio de Padua, esta acción secundaria se escinde en dos acciones diferentes que atañen a personajes particulares, de extensión moderada, con idénticos sistemas de engarce y que finalizan en rigor antes del fin de la comedia. Su imbricación en la trama general se produce también a través de un mismo mecanismo de composición que ejemplifica muy bien el modus operandi de Montalbán.

El tercer bloque escénico de la primera jornada se abre con la presencia en escena de dos galanes, Aristeo y Rodulfo, entretenidos en cortejar a una dama que casualmente comparten sin saberlo. Se establece así un triángulo amoroso donde la amistad queda relegada por los celos, la desconfianza y la enemistad (fol. 161r):

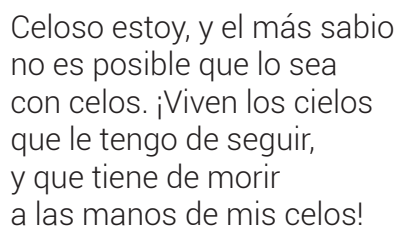

La apenas esbozada venganza queda interrumpido por la llegada inesperada de unos foliones que van a dar una serenata a la ventana de una tal Belisa y por la entrada en escena de fray Domingo, fray Pedro y Antonio ya vestido con los hábitos de la orden franciscana. La interrupción accidental de las tribulaciones de Rodulfo por la llegada de los religiosos es el engarce mecanicista que emplea Montalbán para insertar esta acción en la trama principal. Después, la acción secundaria, de poca extensión, desaparece de escena y es sustituida por otro bloque escénico que dramatiza en escena la tristeza del padre de Antonio, Martín de Bullones, y su amigo Anselmo, que llegan solo a tiempo de ver cómo se aleja la nave en la que va el santo. Como se verá, el orden de los bloques y la presencia del padre de Antonio después del conflicto amoroso de Aristeo y Rodulfo es repetido de nuevo cuando se retoma el hilo de esta historia secundaria, que vuelve a aparecer en el tercer bloque escénico de la segunda jornada. Aristeo ha matado a su contrincante por celos y ha escondido el cadáver en un corral perteneciente a la casa de Martín de Bullones, Aristeo se encuentra lleno de remordimientos porque la justicia ha prendido al padre de Antonio a través de falsos testimonios («Mirad, si es justa causa que esté triste / pues paga un inocente mi delito», fol. 169r) en presencia de Delio, que se convierte en cómplice de la confesión de Aristeo. Martín de Bullones recorre las calles «de luto y una soga a la garganta, y en las manos atadas un Cristo» (fol. 169r), en una escena lastimosa en la que suplica a su verdugo no pasar por su casa y herir de muerte a María su esposa, que ignora su estado. La negativa del verdugo de evitar la vergüenza pública termina con María a punto de arrojarse al vacío y la llegada milagrosa de san Antonio en una apariencia para resucitar a Rudolfo que, «muy sangriento» (fol. 170r), libra con su testimonio al inocente Martín. La disgre- 
gación de la acción secundaria a través del milagro de san Antonio, termina igual que la jornada anterior de forma abrupta ${ }^{14}$.

La siguiente acción secundaria, de igual rango que la anterior, se desarrolla más tarde en el segundo bloque de la jornada segunda. Es la historia amorosa entre Federico y Rosamira, mujer casada que este desea conquistar a toda costa aprovechando que su marido se encuentra en el frente. Federico es notario del obispo pero no duda en poner todo su caudal a los pies de Rosamira, llena de remordimientos por aceptar los requiebros amorosos del galán (fol. 166v):

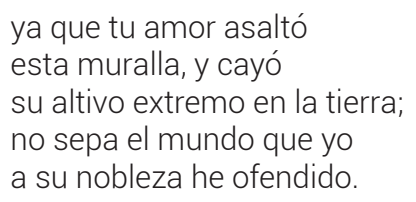

De nuevo, el engarce se realiza a través de la presencia en escena de fray Domingo que enlaza la acción secundaria de Federico con la trama principal de San Antonio. La mención del sermón capta la atención de la dubitosa Rosamira que acepta escucharlo, torciendo así los planes libidinosos de Federico, y, por ende, el plan trazado por el demonio para conseguir ambas almas. El desarrollo de este cuadro termina con la visión milagrosa del esforzado marido luchando contra los enemigos infieles y la conversión definitiva de Rosamira que abandona al despechado Federico. Su vuelta es casi inmediata y se produce al inicio de la tercera jornada donde se diseña en escena la conversión de Federico que en boca de fray Domingo es (fol. 167r):

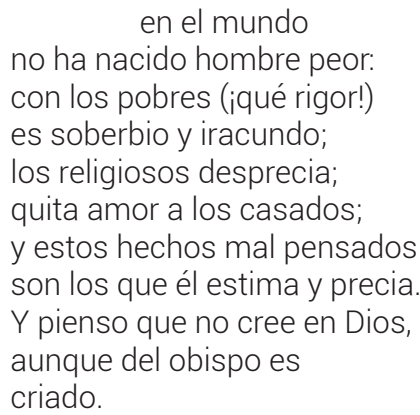

Pero nada escapa al poder de san Antonio que en tono profético pronostica la salvación de su alma pecadora, para ser después incapaz de controlar su llanto desconsolado ante el anuncio de Delio ${ }^{15}$ de partir con el obispo y Federico en busca de la gloria del martirio (fol. 171r):

14. No hay tiempo que perder, pues el santo debe acabar un sermón apenas iniciado lo que le lleva de nuevo a no despedirse de sus padres (fol. 170r).

15. Como su conducta es y será reprobable, san Antonio es una correa de transmisión de la señales de Dios que anuncian el castigo y no la gloria para Delio: «iAy, Delio, que no naciste / para tan alta ventura!» (fol. 171v). 


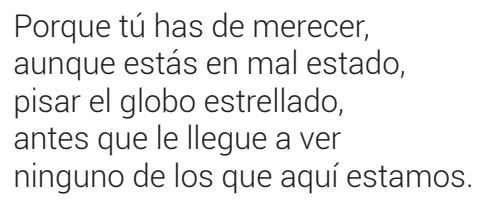

Y así, en el tercer bloque escénico de la tercera jornada, en lucha desigual contra los infieles y los soldados del cónsul Lelio, encontrará Delio la condenación al negar por cobardía el martirio y la fe de Cristo. Por contra, Federico, arrepentido de sus pecados, abrazará el martirio con gozo (fol. 174r):

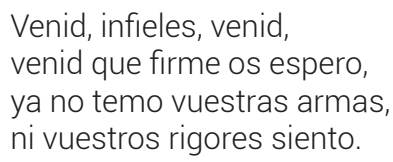

Salvado Federico, gratificado antes de abandonar el mundo terrenal con la visión de san Francisco y san Antonio, aparecerá después vestido de gloria -«aludiendo a la vestidura antigua de que habla la Sagrada Escritura, que es rubicunda en los mártires y blanca en los confesores», como señala Autoridades ${ }^{16}$ - para ejemplo de los pecadores arrepentidos.

Otra cuestión interesante atañe a los principios rectores de la estructuración de la comedia a partir de la acumulación variable de segmentos de acción o de estructuras métricas que configuran distintos niveles de escritura. Pero en el caso de las comedias hagiográficas, de algunas de ellas mejor dicho, cabe contemplar una estructuración basada en la disposición correlativa de hitos escenográficos. Este posible sistema de segmentación solo es aplicable a aquellas comedias donde la puesta en escena es significativa y determinante en el desarrollo de la acción. En el caso de El divino portugués, san Antonio de Padua, resulta plausible esta posible estructuración. Además, se puede advertir en ella una gradación sostenida y climática hacia una especie de apoteosis final. Los inicios de la comedia son más bien convencionales. Aparece en escena un oratorio y en una silla leyendo un libro la figura de san Antonio (fol. 155r), pero pronto se produce una primera torsión escénica con la entrada en «figura espantosa con cadenas» del demonio. Sin embargo, la presencia de lo verosímil maravilloso, que permite la inserción de elementos y motivos por encima de lo que puede tomarse como verdadero, no toma cuerpo en esta primera jornada y su desarrollo transita por los cauces ordinarios de la tramoya teatral. Apenas cabe reseñar al final la mención de una nave («Descúbrese una nave dando vuelta y en ella los tres frailes», fol. 163r) que desaparece enseguida

16. Una explicación completa y pertinente la da el mismo Calderón en La vida es sueño (segunda versión), p. 1394: «¿Quién es el hombre, Señor, / que tanto le magnificas? [...] / Y aun en más le sublimaste, / pues siguiendo el esplendor / de la Gracia, de tu honor / y gloria le coronaste / vistiendo su desnudez / rico, aparente vestido, / que en el místico sentido / significará tal vez / la cándida estola hermosa / que de virtudes tesoro / será en el ropaje de oro / que dé el esposo a la esposa». Y más documentación sobre las connotaciones de la estola como vestido de gloria, honor, triunfo e inmortalidad en C. a Lapide, IX, 440, 1; XXI, 151, 2; 171, 1 . 
del tablado. La segunda jornada representa un paso más en la complicación de la tramoya. La escenografía se adentra con mayor decisión en el terreno de lo inverosímil consensuado, pues es necesario para mantener la tensión dramática la dramatización en escena de los milagros que va realizando el santo en escena. La primera intervención milagrosa transcurre en un plano referencial discursivo. Es articulada mediante la palabra y su poder evocador a través del demonio y su civil acción de arrojar «granizo, rayos y agua» (fol. 167v) para estorbar el sermón de san Antonio Pero el santo obra el milagro y detiene la tormenta (fol. 167v):

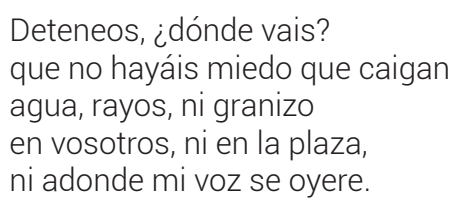

De igual manera, la materialización del segundo milagro también se realiza a través de un enunciado verbal, pues nada parece indicar que el relato de la visión del marido de Rosamira se lleve a cabo de manera efectiva en escena ${ }^{17}$. Es patente, por tanto, la acumulación de hechos maravillosos en escena, relacionados con los milagros del santo. No descritos desde una perspectiva visual hasta que el demonio, despojado al fin de su falso traje de galán, aparece de nuevo sobre una tramoya con apariencia espantosa ${ }^{18}$. La presencia por segunda vez del demonio en su verdadera dimensión monstruosa es un punto de inflexión para la puesta en escena de la comedia, pues a partir de ese momento aumenta el grado de la complejidad visual escenográfica con la plasmación en escena del tercer milagro del santo: «Al querer echarse por el balcón [María, esposa de Martín] suena música y viene san Antonio por el aire en una aparición, que se pueda quitar luego della» (fol. $169 \mathrm{v})$, con la aparición acto seguido de Rodulfo resucitado, «vestido como antes muy sangriento» (fol. 170r).

La tercera jornada es, en cierta medida, la apoteosis escenográfica y la culminación visual de la estructuración gradativa de lo sobrenatural. Pese a que la jornada arranca con la puesta en escena del cuarto milagro de forma poco espectacular - la llegada de los animales invitados por san Antonio a su sermón, cuya acotación deja abierta la puerta a múltiples interpretaciones escenográficas, «Salen los animales que puedan» (fol. 172r) - el tono que adquiere la comedia en el último bloque escénico es de una total preponderancia de la escenografía por encima de otros elementos constitutivos del drama. Delio es fulminado por un rayo: «Baja un rayo y húndese Delio» (fol. 173v); para terminar con una elaborada puesta en escena de una apariencia que recoge los rasgos iconográficos tradicionales de san Antonio y san Francisco (fol. 174v): «Al son de chirimías se descubre a un lado san Antonio con un niño Jesús en los brazos, y al otro san Francisco con Cristo, imprimiéndole las llagas», complementada en los versos siguientes por la visión aleccionadora

17. «Vuelve la vista y repara / en el que armado de acero / entre enemigas escuadras / está por la fe de Dios / blandiendo la fuerte espada» (fol. 168r).

18. «Da vuelta una tramoya con el demonio y sale una figura espantosa» (fol. 168r). 
de Federico como trasunto del pecador arrepentido y partícipe en la gloria de Dios (fol. 175v), y contrarrestada por la visión de Delio, emergiendo del infierno por un escotillón envuelto en llamas ${ }^{19}$.

Otra cuestión reseñable es la temporalidad de la comedia y la disposición en la traza argumental de los sucesivos episodios de la vida del protagonista. Por lo común, la comedia hagiográfica presenta dos modelos de figuras principales que influyen en el diseño de cada obra en particular: la presentación de una biografía de un pecador arrepentido, o, por el contrario, una biografía aleccionadora en su conjunto, sin necesidad de una progresiva evolución hacia la santidad. La mediación de un pecador arrepentido configura la obra hagiográfica como un ejemplo a contrario, donde lo sustancioso es la vertiente plástica de su vida pecadora y su apoteósica conversión final desde una perspectiva catequética. Este tipo de escritura posibilita abundantes cambios espacio-temporales por ser necesaria la dramatización de hitos relevantes de la biografía del pecador arrepentido. Pero hay otras posibilidades estructurales algo diferentes, como ocurre en esta comedia de Montalbán, en las que el protagonista pertenece a ese tipo de personajes que nacen excepcionales en su santidad, y cuya exposición vital responde al ejemplo en positivo de sus cualidades santificadoras. San Antonio, magnífico ejemplo en este caso, determina el armazón dramático de la comedia por dos motivos. El primero tiene que ver con la constatación de pocos saltos cronológicos. De hecho, sólo hay una pequeña diferencia temporal entre la primera jornada que termina con el lento surcar de la nave que transporta a tierra de infieles a los frailes franciscanos (entre ellos a san Antonio), y el inicio de la segunda en tierras italianas después del frustrado viaje a Marruecos (por razones un tanto rocambolescas, dicho sea de paso ${ }^{20}$ ). El lapso temporal es mínimo y no vuelve a producirse entre las dos siguientes jornadas. En el segundo, dada la azarosa biográfica de san Antonio, el dramaturgo se cuida mucho en señalar que la materia historial de toda la comedia obedece a una selección de temas y motivos. Quedan fuera otros muchos, suficientes para la pertinente escritura de una segunda parte (fol. 176r):

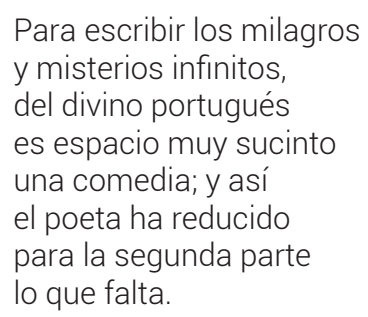

Se pueden extraer dos consecuencias de esto último. Aparte de la formulación conclusiva tópica de anuncio de segundas partes que nunca se escriben, la selección de la materia histórica se subordina por completo al designio catequético (y espectacular también). Además, dada la cantidad de noticias sobre la vida del

19. «Sale Delio entre llamas de fuego, de debajo del tablado» (fol. 175v).

20. Montalbán se valió de la economía dramática para simplificar las verdaderas razones del frustrado viaje a Marruecos de san Antonio, que históricamente fue debido a su convalecencia por enfermedad. 
santo portugués, se hace difícil discernir una fuente histórica precisa, pues la materia biográfica se haya diseminada por numerosos sustratos textuales, con formas poco precisas, y cuya identificación es a veces un trabajo estéril.

Para terminar, voy a dedicar unas pocas líneas a un asunto llamativo relativo al diseño y desarrollo del personaje del gracioso. Se suele producir en este tipo de comedias una modulación característica al desplazarse este tipo dramático hacia la figura del donado o fraile lego, que refina su comicidad escatológica para crear un nuevo registro mixto que bascula entre la defensa de la fe $-y$ la inquebrantable confianza en Dios - y cierto comportamiento cercano al del rústico simple, con continuas referencias autocríticas. En la comedia de Montalbán, el peso de esta transformación recae sobre fray Domingo, declarado paladín contra los infieles (fol. $158 r):$

$$
\begin{aligned}
& \text { Perros, fray Domingo soy } \\
& \text { y Cristo es Dios, mirad hoy } \\
& \text { en mí vuestra muerte fiera. } \\
& \text { Cristo es el Dios verdadero, } \\
& \text { y el que los soberbios doma. } \\
& \text { Esto es cierto, que Mahoma } \\
& \text { es un bellaco arriero. } \\
& \text { Creed en Cristo, perrazos, } \\
& \text { y si su error los esfuerza } \\
& \text { haré que lo hagan por fuerza } \\
& \text { a palos y a capillazos. }
\end{aligned}
$$

Es una mixtura curiosa entre un registro con ciertas dosis de comicidad, con abundancia de apelativos degradantes contra los herejes de la fe, y una extensa nómina de acciones heroicas que lo acercan mucho al santo protagonista (y lo alejan del tipo de bobo arriba señalado ${ }^{21}$ ). En el lado opuesto se encuentra la figura del protagonista, ensalzado y convertido en modelo de virtud, incluso desde la propia apariencia física (fols. 164r-v):

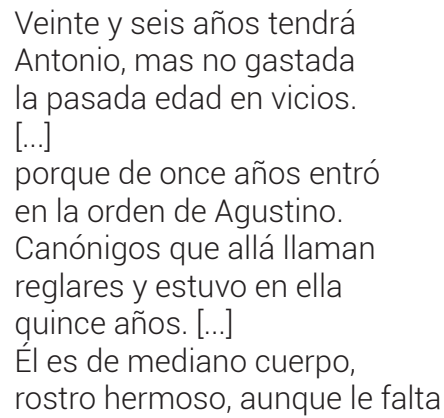

21. Recuérdese que al final de la tercera jornada su discurso es en parte el responsable de la conversión de Federico y de la aceptación alegre de su martirio: «Escarmienta en Delio, amigo, / y toma divino ejemplo / en el obispo dichoso, / que de sangre tiñó el suelo / por defender nuestra fe: / esto solo te aconsejo» (fol. 174r). 


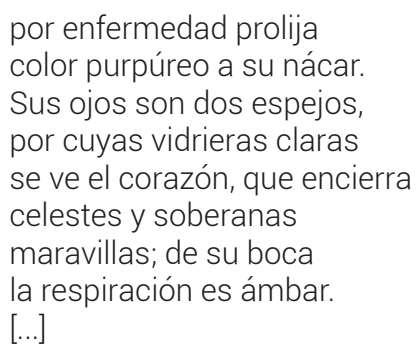

En suma, es patente en Montalbán, pese a su corta vida como dramaturgo, un afán por afianzar una poética particular no exenta de aciertos que revelan las excepcionales dotes que poseía como escritor.

Su conocimiento del teatro y de sus entresijos dramáticos deben situarlo como uno de los dramaturgos más interesantes de su siglo.

\section{BIBLIOGRAFÍA}

Bacon, George William, «The life and dramatic Works of Dr. Juan Pérez de Montalbán», Revue Hispanique, 26, 1912, pp. 1-474.

Biblia Sacra iuxta Vulgatam Clementinam, ed. Alberto Colunga y Lorenzo Turrado, Madrid, BAC, 1994

Calderón de la Barca, Pedro, Obras completas III. Autos sacramentales, ed. Ángel Valbuena Prat, Madrid, Aguilar, 1991 [1952], 2ª ed., 2ª reimp.

Cilveti, Ángel Luis, El demonio en el teatro de Calderón, Valencia, Albatros ediciones, 1977.

Ciruelo, Pedro, Reprobación de las supersticiones y hechicerías, ed. A. V. Ebersole, Valencia, Albatros, 1978.

Lapide, Cornelio a, Commentarii... R. P. Cornelii a Lapide, Paris, Ludovicum Vives, 1878.

Dixon, Víctor, «New (and Ancient) Lights on the Life of Juan Pérez de Montalbán», Bulletin of Spanish Studies, 15, 2013, pp. 509-534.

Dixon, Víctor (ed.), El sufrimiento premiado: comedia famosa atribuida en esta edición, por primera vez, a Lope de Vega Carpio, London, Tamesis Books, 1967.

Duarte, J. Enrique, «Presencias diabólicas en Quevedo», La Perinola, 8, 2004, pp. 125-153

Menéndez Peláez, Jesús, «El teatro hagiográfico en el Siglo de Oro español: aproximación a una encuesta bibliográfica», Memoria Ecclesiae, 24, 2004, pp. 721 802.

Parker, Jack Horace, «Chronology of the plays of Juan Pérez de Montalbán», Publications of Modern Language Association, 67, 1952, pp. 186-210. 
Paz y Mélia, Antonio, Catálogo de las piezas de teatro que se conservan en el Departamento de manuscritos de la Biblioteca Nacional, Madrid, Blass, 1934, vol. I.

Pérez de Montalbán, Juan, El divino portugués, san Antonio de Padua, en Segundo tomo de comedias, Madrid, Imprenta del Reino, 1638, fols. 155r-176r.

Profeti, Maria Grazia, Montalbán: un commediografo dell'età di Lope, Pisa, Università di Pisa, Cursi, 1970.

Profeti, Maria Grazia, Per una bibliografia di Juan Pérez de Montalbán, Verona, Università de Verona, 1976.

Profeti, Maria Grazia, Per una bibliografia di Juan Pérez de Montalbán. Addenda e corrigenda, Verona, Università de Verona, 1982.

Quevedo, Francisco de, Los sueños, ed. Ignacio Arellano, Madrid, Cátedra, 1991.

Suárez de Figueroa, Cristóbal, El pasajero, ed. María Isabel López Bascuñana, Barcelona, Promociones y Publicaciones Universitarias, 1988, 2 vols.

Zugasti, Miguel, «El alma (pura) del rey: visiones preternaturales de los Austrias en el tránsito del purgatorio al cielo», en Sor María de Jesús de Ágreda y la literatura convenctual femenina en el Siglo de Oro, ed. Miguel Zugasti, Soria, Cátedra Internacional Alfonso VIII, 2008, pp. 196-216. 
